\title{
How do the Pore Traits of Hardwoods Affect Sound Absorption Performance of their Cross Sections? - Focusing on 6 Species of Korean Hardwoods
}

\section{Eun-Suk JANG}

Jeonbuk National University

Chun-Won KANG ( $\nabla$ kcwon@jbnu.ac.kr)

Jeonbuk National University

\section{Research Article}

Keywords: sound absorber, natural sound absorber, through-pore porosity, closed-pore porosity, drying, impregnation

Posted Date: April 14th, 2021

DOI: https://doi.org/10.21203/rs.3.rs-403120/v1

License: (c) (i) This work is licensed under a Creative Commons Attribution 4.0 International License.

Read Full License 
How do the pore traits of hardwoods affect sound absorption performance of their cross sections? - Focusing on 6 Species of Korean hardwoods

Eun-Suk JANG Department of Housing Environmental Design, and Research Institute of Human Ecology, College of Human Ecology, Jeonbuk National University, Jeonju 54896, South Korea

Research Institute of Human Ecology, College of Human Ecology, Jeonbuk National University, Jeonju 54896, South Korea

$13 *$ Six species of Korean hardwoods were divided into through-pore, blind-pore, and closed-pore types.

$14 *$ The sound absorption performance of diffuse-porous wood was higher than that of ring-porous wood.

$15 *$ Through-pore porosity was a major variable determining superior sound absorption performance, while closed-pore 16 porosity reduced performance.

\section{Abstract}

An investigation of sound absorption in 6 species of hardwoods according to the pore structure of cross-sections revealed that higher gas permeability was associated with greater sound absorption at high frequencies. In addition, diffuseporous wood exhibited superior sound absorption performance compared with ring-porous wood. Through-pore porosity was associated with improved sound absorption in the cross-sections of all 6 species, while closed-pore porosity was associated with poor sound absorption. The results of these studies could lead to development of hardwood products with superior sound absorption and help elucidate the roles of porosity in drying, impregnation, and thermal insulation properties of wood.

Keywords: sound absorber, natural sound absorber, through-pore porosity, closed-pore porosity, drying, impregnation 
Noise pollution is an inevitable result of industrial development, increasing population density, and urbanization. Longterm exposure reportedly leads to respiratory and cardiocerebrovascular diseases as well as stress ${ }^{1-4}$. Noise pollution can be minimized through active methods that generate "mirror noise" to reduce the amplitude of noise ${ }^{5}$ and through passive methods that employ sound absorbers ${ }^{6}$. Active methods can effectively reduce noise levels but require continuous energy input. Most building designs use passive technologies. According to the Report of Acoustic Insulation Market published by MarketsandMarkets Research Private Ltd. in 2017, the market for sound absorbers and insulators is expected to grow from $\$ 108.3$ billion in 2016 to $\$ 15.1$ billion by 2022 , an annual average growth rate of $5.8 \%{ }^{7}$.

Traditionally, glass and mineral wools were used as sound-absorbing materials. However, these materials can cause cancer in humans ${ }^{8}$ and are difficult to recycle ${ }^{9}$. As a result, natural fiber is emerging as an inexpensive, lightweight, and environmentally superior alternative to glass fiber ${ }^{10}$.

Considerable research attention is being paid to the sound-absorbing potential of natural fibers ${ }^{11-13}$. Most of these materials are composed of agricultural by-products such as rice husks and straw, coir fiber, jute, and kenaf. However, products made from such fibers are not durable and tend to exhibit short service lives ${ }^{14}$.

Wood is an environmentally friendly material used as a building material from prehistoric times to the present, and it offers superior physical properties and durability compared with many other natural materials ${ }^{15}$. Wood is an anisotropic material with different physical properties depending on the cut section ${ }^{16}$. From an acoustic point of view, wood reflects sound as it enters a radial or tangential section, but cross-sections can absorb sound ${ }^{17}$. Because there are more pores in a wooden cross-section compared with radial and tangential sections. When sound waves are incident on the void structure, sound energy hitting the wall inside a pore is converted to heat energy and lost. Therefore, it is possible to design a natural sound absorber using the pore structure of wood.

The sound-absorbing characteristics of cross-sections of wood have been studied from anatomical and physical perspectives. For example, Kang, et al. ${ }^{18}$ used the morphologies of cross-sections of kagikazura (Uncaria rhynchophylla) and Japanese larch (Larix kaemferi) to identify the anatomical characteristics of wood that produce effective sound absorption. The authors reported that large vessels were scattered throughout the cross-sections, and that sound absorption was excellent in hardwoods in which the vessel elements were connected by simple perforates. However, the tyloses of vessels increased air resistance, hindering sound absorption and suggesting that the sound absorption performance of diffuse-porous wood in which vessels are widely distributed would be superior to that of softwoods composed of tracheids ${ }^{19}$.

From the physical point of view, sound absorption is closely and proportionately related to gas permeability ${ }^{20-23}$. In general, hardwoods tend to exhibit greater permeability compared with softwoods ${ }^{24}$. Therefore, cross-sections composed of a hardwood species should demonstrate superior sound-absorbing performance.

We examined the anatomical and physical features that influence sound absorption in wood but found it difficult to compare our results with those of previous studies, as few reports have been published regarding the difference in sound absorption properties between ring-porous and diffuse-porous species. In addition, little is known about the changes in 
sound absorption coefficient (SAC) according to the diameter of through-pore, blind-pore, and closed-pore types of wood based on the effect on gas permeability.

We attempted to investigate the characteristics of cross-sections of hardwoods using porous materials. We also tried to determine how porosity affects the sound absorption performance of hardwood materials. In this study, 6 species of hardwoods that grow naturally in Korea were selected. The gas permeability, pore size, and porosity of all 6 species were assessed according to pore type based on International Union of Pure and Applied Chemistry (IUPAC) criteria, and the differences in pore structures of ring-porous and diffuse-porous specimens were analyzed. The effect of difference in pore structure on sound absorption performance was analyzed and tested for statistical significance.

Our findings should help optimize techniques for impregnation and drying of wood products for use as thermal and acoustic insulators.

\section{Materials and Methods}

\section{Sample preparation}

Air-dried timber samples of the 6 species of Korean hardwoods $(100 \mathrm{~mm}$, tangential $\times 100 \mathrm{~mm}$, radial $\times 1,000 \mathrm{~mm}$, longitudinal) were supplied by Jeonil Timber Co., Ltd. The timbers were turned into cylindrical rods $2.9 \mathrm{~mm}$ in diameter using a lathe and then cut into slices $10 \mathrm{~mm}$ thick using a table saw. From the resulting disks, 10-15 intact specimens of each species without knots and cracks were selected. All specimens were manufactured in Saehan Timber Co., Ltd (Goyang-si, Gyeonggi-do, Republic of Korea). Figure 1 shows the preparation process of the specimens.

Table 1 shows the basic physical properties and vessel arrangement of the 6 species of Korean hardwoods. Their common and scientific names were collected from the book "Wood anatomy of Korean species," published in $2015{ }^{25}$.

Fig. 1. Specimen preparation process.

Table 1 Information on the six species of hardwoods

\section{Morphological analysis by scanning electron microscopy}

Scanning electron microscopy (SEM) was used to observe the shape of the specimen vessels. For pretreatment, they were cut into cubes $(4 \mathrm{~mm}$, tangential $\times 4 \mathrm{~mm}$, radial, $\times 4 \mathrm{~mm}$, longitudinal), immersed in water for softening, and placed in a vacuum chamber at $-0.1 \mathrm{MPa}$ for $60 \mathrm{~min}$. The surface of each cross-section was shaved using a microtome and air-dried in an oven at $50{ }^{\circ} \mathrm{C}$ for $5 \mathrm{~h}$. After the specimens were completely dried, their surfaces were coated with gold using an ion sputter. After all pretreatment processes were complete, the surfaces were observed at $100 \times$ 
magnification using a Genesis-1000 microscope (Emcrafts, Sungnam, Korea).

\section{$97 \quad$ Gas permeability and pore size analysis}

98 The gas permeability of each specimen was measured by capillary flow porometry (model: CFP-1200AEL, Porous Material Inc., Ithaca, NY, USA). Two O-rings were inserted above and below the specimen to prevent air from leaking between the chamber wall and the edge of the specimen. The differential air pressure was set in the fiber direction from 0 to approximately $1 \mathrm{~atm}$. The pressure applied to the specimen and the flow rate of air through the specimen were measured. At this time, the Darcy permeability constant $(C)$ was calculated automatically using software for a capillary flow porometer ${ }^{26,27}$ and Equation 1:

$C=8 F T V / \pi D^{2}\left(P^{2}-1\right)$

where $C$ is the Darcy permeability constant, $F$ is flow, $T$ is sample thickness, $V$ is viscosity of air, $D$ is sample diameter; and $P$ is pressure.

The size of the pores of the specimens was measured using the same equipment as involved in measuring gas permeability. This method, which follows ASTM F-136 standards, measures the constricted parts - the "throat diameter" ${ }^{28}$ — of the through pores ${ }^{26,29-31}$. After gas permeability was measured, the specimen was immersed in Galwick solution (surface tension 15.6 dyne $/ \mathrm{cm}^{2}$ ) and placed in a vacuum chamber at $-0.1 \mathrm{MPa}$ for $15 \mathrm{~min}$. As Galwick solution has a much lower surface tension than other liquids, it can easily penetrate the pores of the specimen. The wetted specimen was placed inside the sample chamber, and air was applied in the fiber direction. As the inside of the pore was filled with Galwick solution, it did not emerge at the initial pressure, but as the pressure increased, the solution in the pores began to extrude. The pressure at which the solution began to extrude was measured, and the maximum and mean pore sizes were calculated using capillary flow porometry software and Equation $2^{26,27}$ :

$$
D=\frac{C \tau}{p}--(2)
$$

where $D$ is the limiting diameter; $\tau$ is surface tension; $p$ is pressure and $C$ is a constant of 2860 when $p$ is in $\mathrm{Pa}, 2.15$ when $p$ is in $\mathrm{cm} \mathrm{Hg}$, and 0.415 when $p$ is in psi.

\section{Porosity analysis}

According to the IUPAC technical report, "Recommendations for the characterization of porous solids," which was published in 1994 by ${ }^{32}$, pores in solid porous materials can be classified into three types (Fig. 2). Open pores, which 
are connected to the outside, can be divided into through pores and blind pores. The open ends of a through pore create a passage through which fluid can flow. Blind pores have only one open end, while closed pores are contained within the material and are not connected to the outside. The classification of porosity of the specimens used in this study followed a method described in the authors' previous studies ${ }^{27,33,34}$.

Fig. 2. Pore types of solid porous materials according to IUPAC criteria.

For convenience, the density of wood was assumed to be $1.5 \mathrm{~g} / \mathrm{cc}$, and the total porosity of hardwood was calculated using Equation 3:

$\phi_{\text {total }}(\%)=\left(1-\frac{1.5}{\rho_{b}}\right) \times 100$

A gas pycnometer (model: PYC-100A-1, Porous Material Inc., Ithaca, NY, USA) was used to determine the open-pore porosity of circular hardwood specimens following ISO 12154 standard, and the skeleton density of the specimens was obtained at the pressure of helium gas that penetrated the open pores. The open-pore porosity was calculated by Equation 4:

$$
\phi_{\text {open }}(\%)=\left(1-\frac{\rho_{\mathrm{s}}}{\rho_{\mathrm{b}}}\right) \times 100
$$

where $\rho_{\mathrm{s}}$ is skeleton density of specimen, and $\rho_{\mathrm{b}}$ is bulk density of the specimen.

Closed-pore porosity was calculated by subtracting open-pore porosity from total porosity (Equation 5):

$$
\phi_{\text {closed }}(\%)=\phi_{\text {total }}-\phi_{\text {open }}---(5)
$$

To distinguish between blind-pore and through-pore porosity, specimens were immersed in Galwick solution, placed in a vacuum chamber, and decompressed at $-0.1 \mathrm{MPa}$ for approximately 15 minutes. The Galwick solution impregnated both through pores and blind pores. The specimens were placed in the chamber of the capillary flow porometer, and when air pressure was applied in the fiber direction, the Galwick solution inside the through pore was extruded. It can be assumed that the solution in blind pores did not extrude. The volume of blind pores can be determined using the 
weight difference from the specimen's dry state, and the blind-pore porosity can be calculated using Equation 6 . Through-pore porosity was obtained by subtracting blind-pore porosity from open-pore porosity. This process was performed simultaneously with pore-size measurements.

$$
\phi_{\text {blind }}(\%)=\left(\frac{\left(m_{1}-m_{0}\right) / \rho_{G}}{V}\right) \times 100---(6)
$$

where $\mathrm{m}_{0}$ is the mass of the dried state of the specimen, $\mathrm{m}_{1}$ is the mass of the specimen after extrusion of Galwick solution, $V$ is the volume of the specimen, and $\rho_{\mathrm{G}}$ is the specific gravity of Galwick solution (1.79)

$$
\phi_{\text {through }}(\%)=\phi_{\text {open }}-\phi_{\text {blind }}---(7)
$$

\section{Sound absorption coefficient (SAC) and noise reduction coefficient}

To measure the SAC, an impedance tube (model: Type 4206, B\&K, Denmark) and a transfer function method that complied with ISO 10534-2 was used. White noise incident on the specimen was applied in the vertical direction. In any material, some sound energy will be absorbed by the specimen and some will be reflected. The sound pressure was measured at two microphones, and the SAC was calculated from the transfer function of the sound pressure.

The frequency range of the SAC was 50 to $6,400 \mathrm{~Hz}$, and SAC values were obtained every $8 \mathrm{~Hz}$. From these values, the software generated a graph with frequency on the $\mathrm{x}$ axis and SAC on the $\mathrm{y}$ axis, with the SAC depending on frequency. A noise reduction coefficient (NRC) supplied by ISO 11654 allows sound absorption to be easily evaluated with a single index. The NRC is the average value of the SAC at 250,500, 1,000 and 2,000 Hz, as shown in Equation 8.

$\mathrm{NRC}=\frac{\alpha_{250}+\alpha_{500}+\alpha_{1,000}+\alpha_{2,000}}{4}---(8)$

where $\alpha_{250}$ is the $\mathrm{SAC}$ at $250 \mathrm{~Hz}, \alpha_{500}$ is the $\mathrm{SAC}$ at $500 \mathrm{~Hz}, \alpha_{1000}$ is the $\mathrm{SAC}$ at $1,000 \mathrm{~Hz}$, and $\alpha_{2000}$ is the SAC at 2,000 $\mathrm{Hz}$.

Because the NRC is a single index, evaluation of sound absorption performance is limited by frequency. In this study, the frequency range was divided into $250-500,500-1,000,1,000-2,000$, and 2,000-6,400 Hz ranges, and the average SAC was calculated.

Before measurement, three methods of calibration (determining impedance by volume velocity sensor, reference 
sample, and wave reflection) were performed ${ }^{35}$. In addition, an O-ring was inserted at the front end of the specimen to prevent experimental errors due to the air gap between the cylindrical specimen and the inner wall in the impedance tube ${ }^{36}$. All specimens were measured at an atmospheric pressure of $1037.00 \mathrm{hPa}$, a temperature of $18.80{ }^{\circ} \mathrm{C}$, and a relative humidity of $32.00 \%$. The velocity of sound was $342.53 \mathrm{~m} / \mathrm{s}$, the density of air was $1.235 \mathrm{~kg} / \mathrm{m}^{3}$, and the characteristic impedance of air was $423.1 \mathrm{~Pa} /(\mathrm{m} / \mathrm{s})$. The experimental procedures for this study are illustrated in Fig. 3.

Fig. 3. Schematic of the experimental procedure.

\section{Statistical analysis}

Student's t-test was performed to verify the statistical significance of the average difference in ring-porous and diffuseporous samples. A simple regression analysis was performed to investigate how gas permeability affected sound absorption. Finally, Pearson's correlation analysis was performed to analyze the individual effects of various porous traits on sound absorption using SPSS v26, (IBM Corp, USA).

\section{Results and discussion}

\section{Morphologies of cross-sections of 6 species of Korean hardwood}

Figure 4 depicts SEM images of the cross-sections of the 6 species of Korean hardwoods. The arrangements of the vessels of Red toon, Korean castanea, and East Asian hackberry were typical of ring-porous wood. The vessels were large in spring wood, gradually becoming smaller as they progressed toward autumn wood. However, Korean aspen, Oriental plane trees, and East Asian alder exhibited arrangements typical of diffuse-porous wood. Their vessel diameters were smaller than those of ring-porous wood and evenly arranged throughout the growth rings. The morphologies of the cross-section of the 6 species were consistent with previous reports ${ }^{25}$.

Fig. 4. The morphologies of the 6 species of cross-sectional hardwoods by SEM.

\section{Results of gas permeability and pore size analysis}

Table 2 provides the gas permeability, maximum pore size, and mean pore size of the 6 species. Gas permeability in the Korean aspen was 36.002 (standard deviation [SD], 3.409) Darcy, which was highest among the 6 species, followed by that of the East Asian hackberry at 10.787 (SD: 1.036), the Oriental plane tree at 9.923 (SD: 3.224), Red toon at 5.750 (SD: 1.499), East Asian alder at 5.528 (SD: 1.105), and Korean castanea at 0.420 (SD: 0.322).

Figure 5 supplies the average difference in gas permeability between diffuse-porous and diffuse-porous specimens. 
The analysis revealed that the permeability of diffuse-porous wood was greater than that of diffuse-porous wood $(\mathrm{t}=$ $-5.582, P<0.001)$.

In the anatomical traits of the 6 species of Korean hardwoods, the vessel diameter of ring-porous wood was larger than that of diffuse-porous wood. However, vessel frequency was greater in diffuse-porous than in ring-porous wood. For this reason, we assumed that the gas permeability of diffuse-porous wood was greater than that of ring-porous wood.

Fig. 5. Average difference in gas permeability between ring-porous wood (Rp) and diffuse-porous wood (D p).

The maximum pore size of ring-porous wood Red toon was 148.201 (SD: 44.342), that of Korean castanea was 97.011 (SD: 60.517), and that for East Asian hackberry was 102.138 (SD: 9.983) $\mu \mathrm{m}$. In diffuse-porous wood, maximum of Korean aspen was 47.852 (SD: 2.364), 27.5 (SD: 4.823) for oriental plane tree and 7.523 (SD: 0.376) $\mu \mathrm{m}$ for East Asian alder. The mean pore size was 70.251 (SD: 25.732) in ring-porous Red toon, 35.404 (SD: 30.464) in Korean castanea, and 29.237 (SD: 4.074) $\mu \mathrm{m}$ in East Asian hackberry. For diffuse-porous wood, mean pore size of Korean aspen was 22.027 (SD: 1.094), 4.477 (SD: 1.35) for oriental plane tree, and 1.99 (SD: 0.206) $\mu \mathrm{m}$ for East Asian alder.

A capillary flow porometer measures only throat diameter of pores, and the throat of vessel elements in hardwoods is composed of perforated plates. The pore size of a hardwood cross-section measured by a capillary flow porometer is not the vessel diameter but the perforated plate diameter ${ }^{33,37}$.

Figure 6 depicts the difference in average maximum and mean pore sizes between ring-porous and diffuse-porous wood. These values were greater in ring-porous wood than in diffuse-porous wood $(\operatorname{maximum}$ pore size: $\mathrm{t}=10.870, P$ $<0.001$ and mean pore size: $\mathrm{t}=7.412, P<0.001)$.

The difference between ring-porous and diffuse-porous perforated plate diameters was similar to that of their anatomical traits. While the throat diameter of solid porous materials was highly correlated with gas permeability ${ }^{38-40}$, we observed no correlation between pore size and gas permeability. This can be attributed to the larger pores in ringporous wood was larger than in diffuse-porous wood at low vessel frequency. Hardwoods are naturally porous, and their permeability and pore size need to be harmonized to allow sufficient water transport capacity ${ }^{41}$. The pore structure of wood products is different from that of artificially manufactured solid porous materials.

Fig. 6. Average difference of maximum pore and mean pore size between ring-porous wood (Rp) and diff use-porous wood (Dp).

\section{Results of porosity analysis}


Table 2 provides the through-pore, blind-pore, and closed-pore porosity values of the 6 species of Korean hardwoods. Among the species, porosity was highest in Korean aspen at 41.090 (SD: 7.363). The next most porous tree species was the Oriental plane tree at 29.561 (SD: 2.403), followed by East Asian alder at 25.511 (SD: 1.708), East Asian hackberry at 17.936 (SD: 1.965), Korean castanea at 14.620 (SD: 3.541), and Red toon at 12.721 (SD: 4.455).

Figure 7 depicts the average differences in through-pore porosity, blind-pore porosity, and closed-pore porosity between ring-porous wood and diffuse-porous wood. Through-pore porosity and blind-pore porosity of diffuse-porous wood were greater than those of ring-porous wood. However, the closed-pore porosity of ring-porous wood was greater than that of diffuse-porous wood.

The pores of diffuse-porous wood were smaller than those of ring-porous wood, although the through-pore porosity of diffuse-porous wood was greater than that of ring-porous wood. This phenomenon was likely a result of greater gas permeability of diffuse-porous wood compared with ring-porous wood.

Fig. 7. Average difference of maximum and mean pore sizes between ring-porous wood (Rp) and diffuseporous wood $(\mathrm{Dp})$.

\section{Sound absorption performance measured by an impedance tube}

Figure 8 displays SAC according to frequency for the 6 species of hardwoods. In all specimens, the SAC increased with frequency, which is typical of a porous sound absorber ${ }^{42,43}$. Among the 6 species, the NRC of Korean aspen was the highest at 0.217 (SD: 0.009), followed by the Oriental plane tree at 0.167 (SD: 0.015), East Asian hackberry at 0.116 (SD: 0.005), Red toon at 0.115 (SD: 0.007), Korean castanea at 0.103 (SD: 0.012), and East Asian alder at 0.101 (SD: 0.009).

Fig. 8. Sound absorption coefficients for the cross-sections of 6 species of hardwoods.

Figure 9 shows the results of simple linear regression between gas permeability and SAC. Analysis results showed,, F $=12.823, \mathrm{P}<0.001$ for the frequency range $250-500 \mathrm{~Hz} ; \mathrm{F}=134.261, \mathrm{P}<0.001$ for the frequency range $500-1,000 \mathrm{~Hz}$; $\mathrm{F}=227.316, \mathrm{P}<0.001$ for the frequency range $1,000-2,000 \mathrm{~Hz}$; and $\mathrm{F}=492.440, \mathrm{P}<0.001$ for the frequency range 2,000-6,400. The results of the regression models were statistically significant at a level of $1 \%$. The slope of the regression model equation increased from 0.1338 to 0.8558 as frequency increased. In addition, $\mathrm{R}^{2}$ in the frequency range $250-500 \mathrm{~Hz}$ was 0.1338 , that of $500-1,000 \mathrm{~Hz}$ was 0.4443 , that of $1,000-2,000 \mathrm{~Hz}$ was 0.7326 , and that of $2,000-$ $6,400 \mathrm{~Hz}$ was 0.8558 , with a tendency to increase at higher frequencies.

Fig. 9. Results of simple regression analysis between gas permeability and average SAC at $250-500 \mathrm{~Hz}$ 
(a), 500-1,000 Hz (b), 1,000-2,000 Hz (c), 2,000-6,400 Hz (d).

Table 3 lists the results of Pearson's correlation analysis of pore size (maximum and mean), pore type (through-pore porosity, blind-pore porosity, and closed-pore porosity), and average SAC of the 6 species of Korean hardwoods at each frequency range $(250-500,500-1,000,1,000-2,000$, and 2,000-6,400 Hz). The correlation between pore size and average SAC was negative overall. Through-pore porosity and average SAC were positively correlated in all frequency ranges, and closed-pore porosity and average SAC were negatively correlated in all frequency ranges. This confirmed that through-pore porosity is a major contributor to the improvement of overall sound absorption in the 6 Korean hardwoods. Increasing the through-pore porosity of hardwood leads to an improvement in its gas permeability ${ }^{27,33,34}$, which can improve sound absorption performance. However, closed-pore porosity inhibited sound absorption performance in all frequency ranges.

Table 3. Results of Pearson's correlation analysis $(n=85)$.

Figure 10 displays the difference between the average SAC of ring-porous and diffuse-porous specimens. Overall, the sound absorption performance of diffuse-porous wood was superior to that of ring-porous wood $(\mathrm{t}=-16.960, \mathrm{P}<0.001$, average SAC at 250-500 Hz; $\mathrm{t}=-12.629, \mathrm{P}<0.001$, average $\mathrm{SAC}$ at $500-1,000 ; \mathrm{t}=-6.187, \mathrm{P}<0.001$, average SAC at 1,000-2,000; and $\mathrm{t}=-4.344, \mathrm{P}<0.001$, average $\mathrm{SAC}$ at 2,000-6,400 Hz). This is because diffuse-porous wood porosity is greater than that of ring-porous wood, which indicates that diffuse-porous wood has more void space to absorb sound energy.

Fig. 10. Comparison of SACs between ring-porous wood (Rp) and diffuse-porous wood (Dp).

\section{Conclusion}

This study compared the pore structure and sound absorption performance of 6 species of Korean hardwoods. The results can be summarized as follows.

1. The overall SAC curve was consistent with that of a typical porous sound absorber, with low SAC at low frequencies and increasing SAC at higher frequencies.

2. The SAC increased with gas permeability. At higher frequencies, the slope and explanatory power also increased. 
3. The average SAC of diffuse-porous wood was greater than that of ring-porous wood in all frequency ranges.

4. Through-pore porosity and closed-pore porosity had opposite effects on the 6 species of hardwoods. Through-pore porosity contributed to improved sound absorption, while closed-pore porosity decreased sound absorption.

Because this study involved only 6 species of Korea hardwoods, different results might be derived when using other species. If other types of hardwoods are analyzed, it could be possible to develop a predictive model for sound absorption performance based on pore type and pore size of hardwood. In addition, if various physicochemical wood modifications are developed to increase through-pore porosity, which has the greatest impact on sound absorption performance of hardwoods, it might be possible to maximize the sound absorption performance of naturally porous materials. The results of this study are not limited to sound absorption performance in hardwoods, but can be applied more generally to the properties of hardwoods as a porous materials, including insulation, impregnation, and mechanical aspects.

\section{Declaration of Competing Interest}

The authors have no competing interests.

\section{Credits and authorship contribution statement}

ES Jang: Conceptualization, Investigation, Methodology, Experiment, Data analysis, Writing - original draft. CW Kang: Supervision, Writing - review and editing. All authors have read and approved the final manuscript.

\section{Acknowledgments}

This research was supported by the Basic Science Research Program through the National Research Foundation of Korea (NRF) funded by the Ministry of Education (NRF-2019R1I1A3A02059471). It also was supported under the international cooperation program framework managed by the NRF of Korea (NRF-2020K2A9A2A08000181). The authors are thankful to the "Leaders in Industry-university Cooperation+ Project" supported by the Ministry of Education and NRF of Korea.

\section{References}

1 Stansfeld, S. A. \& Matheson, M. P. Noise pollution: non-auditory effects on health. Br Med Bull 68, 243-257 (2003). 
Jariwala, H. J., Syed, H. S., Pandya, M. J. \& Gajera, Y. M. Noise Pollution \& Human Health: A Review. Indoor Built Environ., 1-4 (2017).

Oh, M., Shin, K., Kim, K. \& Shin, J. Influence of noise exposure on cardiocerebrovascular disease in Korea. Sci Total Environ 651, 1867-1876 (2019).

Anees, M. M., Qasim, M. \& Bashir, A. Physiological and physical impact of noise pollution on environment. Earth Science Pakistan 1, 08-11 (2017).

Carme, C., Romerowski, C. \& Clavard, J. in INTER-NOISE and NOISE-CON Congress and Conference Proceedings. 7460-7466 (Institute of Noise Control Engineering).

Fan, X. et al. Environmental noise pollution control of substation by passive vibration and acoustic reduction strategies. Appl Acoust 165, 107305 (2020).

MarketandMarket. Acoustic Insulation Market by Type (Glass Wool, Rock Wool, Foamed Plastics), End-Use Industry (Building \& Construction, Transportation, Manufacturing \& Processing), and Region (Asia Pacific, Europe, North

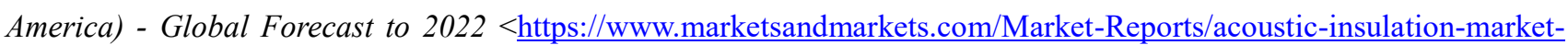
41399747.html> (2017).

Lipworth, L., La Vecchia, C., Bosetti, C. \& McLaughlin, J. K. Occupational exposure to rock wool and glass wool and risk of cancers of the lung and the head and neck: a systematic review and meta-analysis. J. Occup. Environ. Med. 51, 10751087 (2009).

Väntsi, O. \& Kärki, T. Mineral wool waste in Europe: a review of mineral wool waste quantity, quality, and current recycling methods. J. Mater. Cycles Waste Manage. 16, 62-72 (2014).

Joshi, S. V., Drzal, L., Mohanty, A. \& Arora, S. Are natural fiber composites environmentally superior to glass fiber reinforced composites? Composites Part A: Applied Science and Manufacturing 35, 371-376 (2004). Iannace, G. The acoustic characterization of green materials. Building Acoustics 24, 101-113 (2017). Yang, T. et al. Sound Absorption Properties of Natural Fibers: A Review. Sustainability 12, 8477 (2020). Berardi, U. \& Iannace, G. Acoustic characterization of natural fibers for sound absorption applications. Build. Environ. 94, 840-852 (2015).

Wötzel, K., Wirth, R. \& Flake, M. Life cycle studies on hemp fibre reinforced components and ABS for automotive parts. Die Angewandte Makromolekulare Chemie 272, 121-127 (1999).

Asdrubali, F. et al. A review of structural, thermo-physical, acoustical, and environmental properties of wooden materials for building applications. Build. Environ. 114, 307-332 (2017).

Xu, B.-H., Bouchaïr, A., Taazount, M. \& Racher, P. Numerical simulation of embedding strength of glued laminated timber for dowel-type fasteners. J. Wood Sci. 59, 17-23 (2013).

Watanabe, T., Matsumoto, T., Kinoshita, N. \& Hayashi, H. Acoustical study of woods and wood products. J. Japan wood res. soc 13, 177-182 (1967).

Kang, C.-W., Kang, W. \& Kim, G.-C. Sound absorption capability and anatomical features of highly sound absorptive wood. J Korean Wood Sci Technol 38, 292-297 (2010).

Kang, C.-w., Jang, E.-s., Jang, S.-s., Cho, J.-I. \& Kim, N.-h. Effect of Heat Treatment on the Gas Permeability, Sound Absorption Coefficient, and Sound Transmission Loss of Paulownia tomentosa Wood. J Korean Wood Sci Technol 47, 644654 (2019).

Kang, C., Kang, W., Chung, W., Matsumura, J. \& Oda, K. Changes in anatomical features, air permeability and sound absorption capability of wood induced by delignification treatment. J Fac Agric Kyushu Univ 53, 479-483 (2008).

Kang, C.-W., Li, C., Jang, E.-S., Jang, S.-S. \& Kang, H.-Y. Changes in sound absorption capability and air permeability of Malas (Homalium foetidum) specimens after high temperature heat treatment. J Korean Wood Sci Technol 46, 149-154, doi:https://doi.org/10.5658/WOOD.2018.46.2.149 (2018).

Taghiyari, H., Zolfaghari, H., Sadeghi, M., Esmailpour, A. \& Jaffari, A. Correlation between specific gas permeability and sound absorption coefficient in solid wood. J Trop For Sci, 92-100 (2014). 
Kolya, H. \& Kang, C. W. High acoustic absorption properties of hackberry compared to nine different hardwood species: A novel finding for acoustical engineers. Appl Acoust 169, 107475 (2020).

Bao, F., Lu, J. \& Avramidis, S. On the permeability of main wood species in China. Holzforschung 53, 350-354 (1999).

Eum, Y. G. Wood anatomy of Korean species. (Mediawood, 2015).

Jang, E.-S. \& Kang, C.-W. Do Face Masks become Worthless after Only One Use in the COVID-19 Pandemic? Infection \& chemotherapy $\mathbf{5 2}$ (2020).

Jang, E.-S., Yuk, J.-H. \& Kang, C.-W. An experimental study on change of gas permeability depending on pore structures in three species (hinoki, Douglas fir, and hemlock) of softwood. J. Wood Sci. 66, 1-12 (2020).

Li, D., Frey, M. W. \& Joo, Y. L. Characterization of nanofibrous membranes with capillary flow porometry. J. Membr. Sci. 286, 104-114 (2006).

Agarwal, C. et al. Neck-size distributions of through-pores in polymer membranes. J. Membr. Sci. 415, 608-615 (2012).

Gupta, N., Jena, A. \& Gupta, K. Determining the pore Structure of Pore Structure of Individual Layers of Multi-Layered Ceramic Composites. Ceramic Industry 151 (2001).

Jena, A. \& Gupta, K. Characterization of pore structure of filtration media. Fluid/Part. Sep. J. 14, 227-241 (2002).

Rouquerol, J. et al. Recommendations for the characterization of porous solids (Technical Report). Pure Appl Chem 66, 1739-1758, doi:https://doi.org/10.1351/pac199466081739 (1994).

Jang, E.-S., Kang, C.-W. \& Jang, S.-S. Pore characterization in cross section of yellow poplar (Liriodendron tulipifera) wood. J Korean Wood Sci Technol 47, 8-20, doi:https://doi.org/10.5658/WOOD.2019.47.1.8 (2019).

Jang, E.-S. \& Kang, C.-W. Changes in gas permeability and pore structure of wood under heat treating temperature conditions. J. Wood Sci. 65, 1-9, doi:https://doi.org/10.1186/s10086-019-1815-3 (2019).

Boonen, R., Sas, P., Desmet, W., Lauriks, W. \& Vermeir, G. Calibration of the two microphone transfer function method with hard wall impedance measurements at different reference sections. Mechanical Systems and Signal Processing 23, 1662-1671 (2009).

Kolya, H. \& Kang, C.-W. Hygrothermal treated paulownia hardwood reveals enhanced sound absorption coefficient: An effective and facile approach. Appl Acoust 174, 107758 (2021).

Jang, E.-S., Kang, C.-W. \& Jang, S.-S. Comparison of the Mercury Intrusion Porosimerty, Capillary Flow Porometry and Gas Permeability of Eleven Species of Korean Wood. $J$ Korean Wood Sci Technol 46, 681-691, doi:https://doi.org/10.5658/WOOD.2018.46.6.681 (2018).

Encalada, Á., Barzola-Monteses, J. \& Espinoza-Andaluz, M. A Permeability-Throat Diameter Correlation for a Medium Generated with Delaunay Tessellation and Voronoi Algorithm. Transport in Porous Media 132, 201-217 (2020).

Jang, E.-S., Kang, C.-W., Kang, H.-Y. \& Jang, S.-S. Sound Absorption Property of Traditional Korean Natural Wallpaper (Hanji). J Korean Wood Sci Technol 46, 703-712, doi:10.5658/WOOD.2018.46.6.703 (2018).

Patanaik, A. \& Anandjiwala, R. Some studies on water permeability of nonwoven fabrics. Textile research journal 79, 147153 (2009).

Martínez-Cabrera, H. I., Schenk, H. J., Cevallos-Ferriz, S. R. \& Jones, C. S. Integration of vessel traits, wood density, and height in angiosperm shrubs and trees. Am J Bot 98, 915-922 (2011).

Egab, L., Wang, X. \& Fard, M. Acoustical characterisation of porous sound absorbing materials: a review. International Journal of Vehicle Noise and Vibration 10, 129-149, doi:https://doi.org/10.1504/IJVNV.2014.059634 (2014).

Arenas, J. P. \& Crocker, M. J. Recent trends in porous sound-absorbing materials. Sound Vibrat. 44, 12-18 (2010). 
Figures

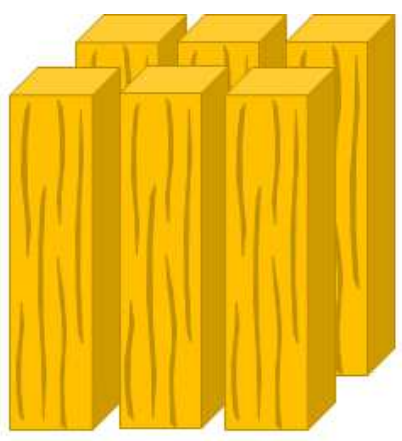

Timbers

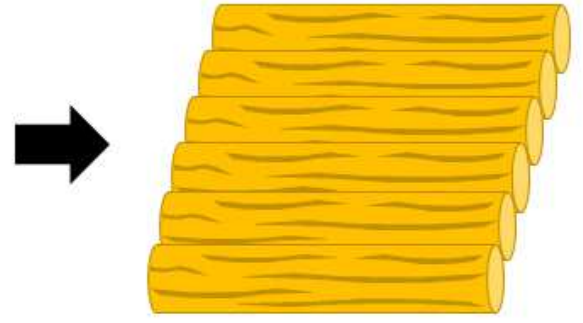

Cylindrical rods

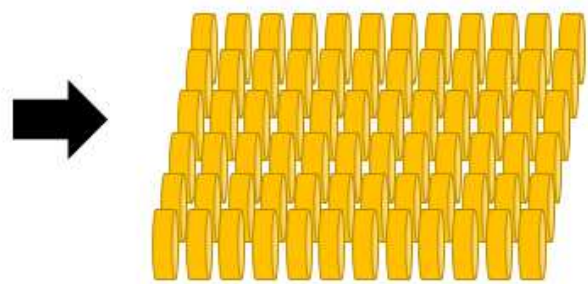

Cylindrical disk specimens

Fig 1. Specimens preparation process

\section{Figure 1}

Specimens preparation process 


\section{Open pore}

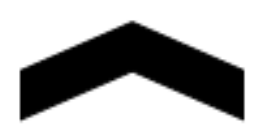

\section{Through pore}

Blind pore

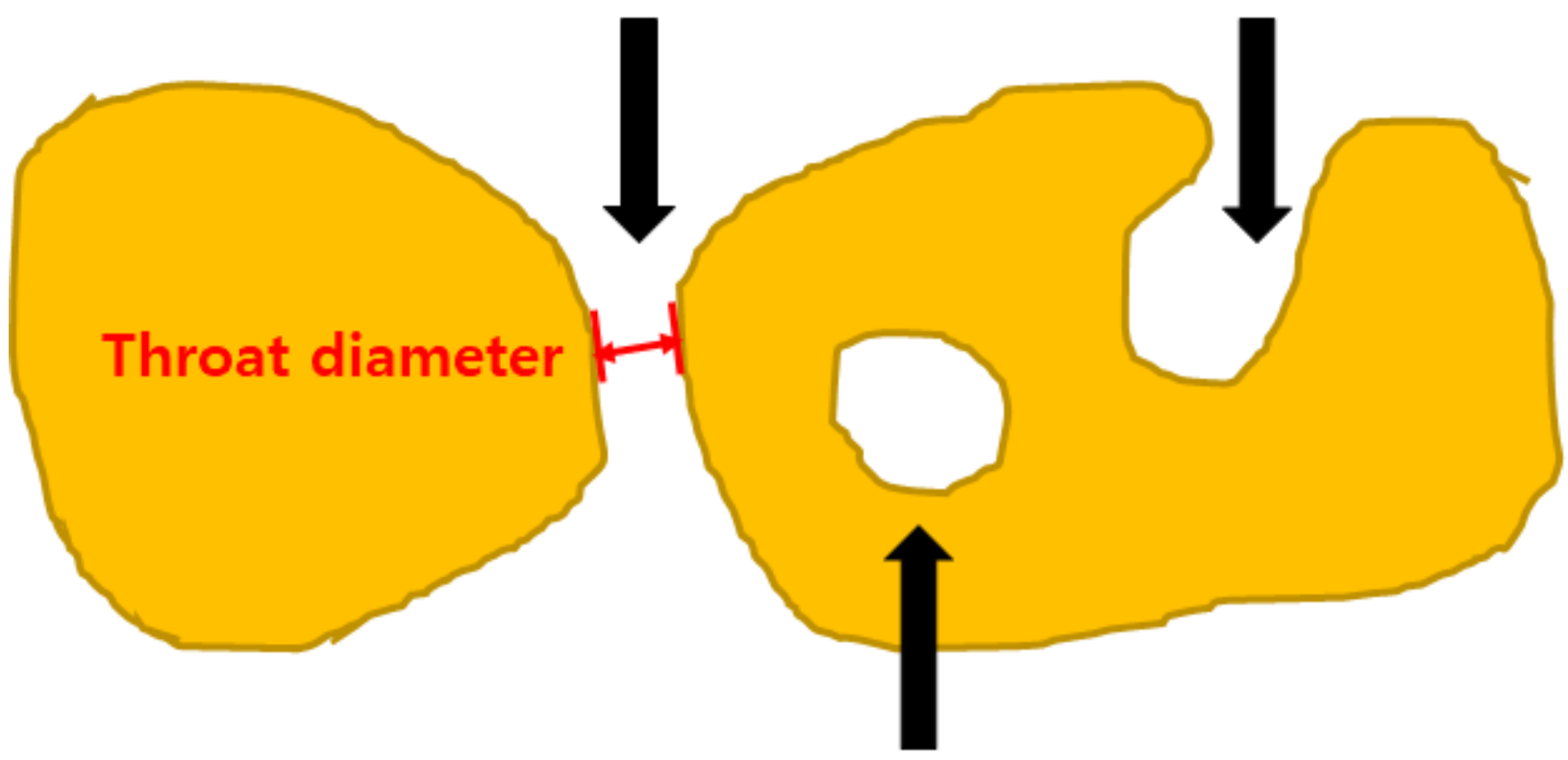

Closed pore

Fig 2. Classification of pore types of solid porous materials based on IUPAC.

Figure 2

Classification of pore types of solid porous materials based on IUPAC. 


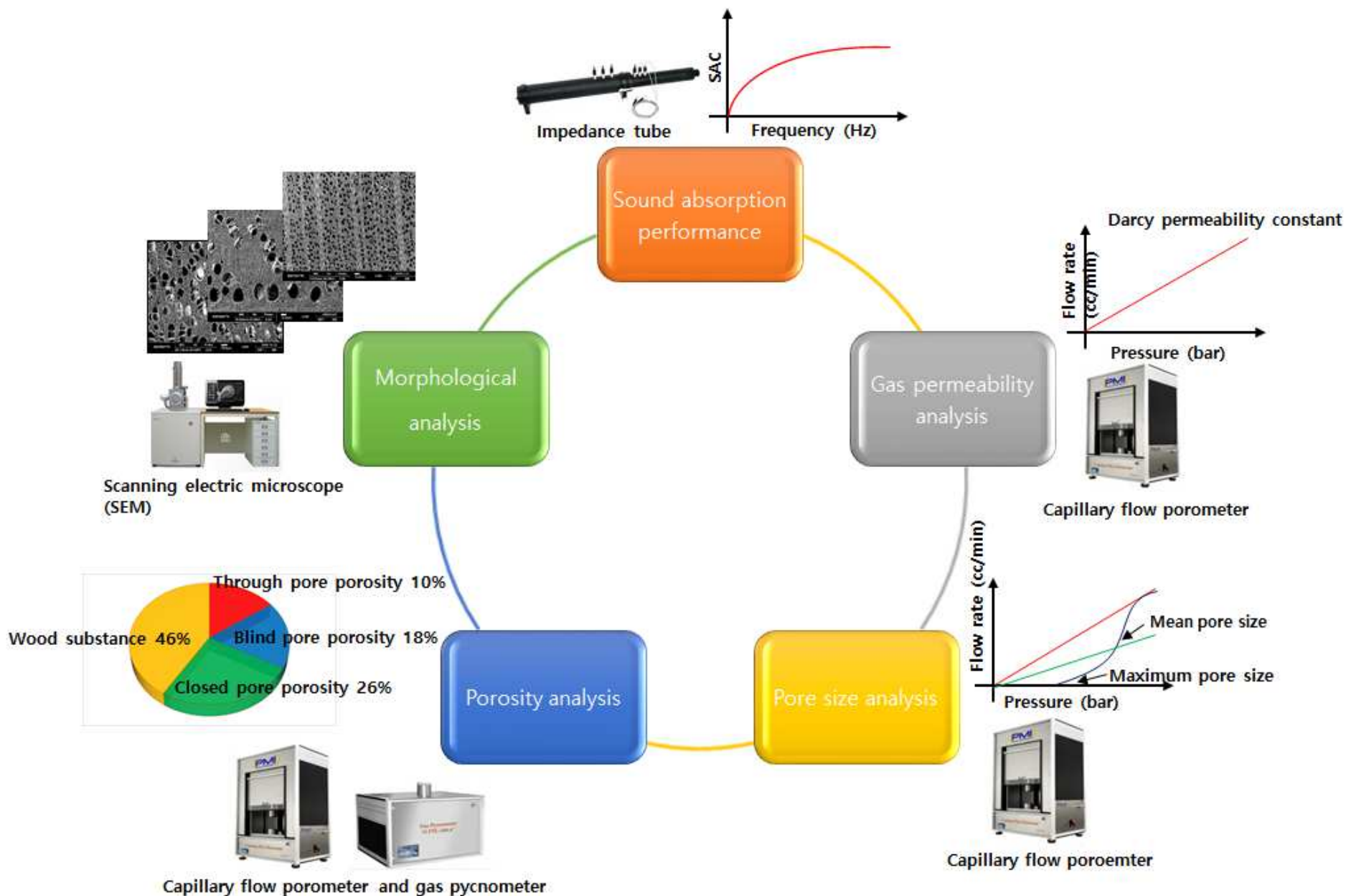

Fig 3. Schematic diagram of the experimental procedure

\section{Figure 3}

Schematic diagram of the experimental procedure 


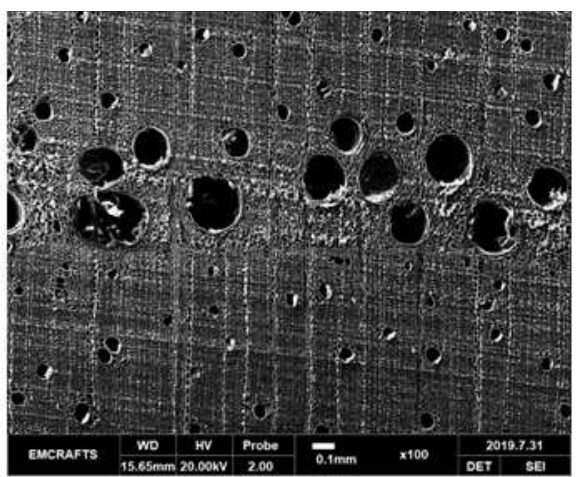

(a) Chinese Cedar

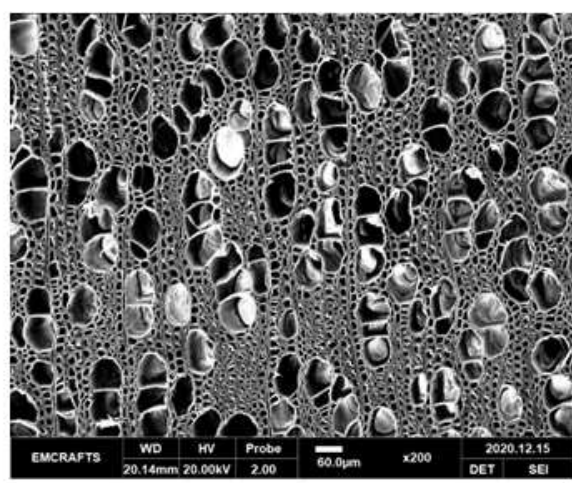

(d) Korean aspen

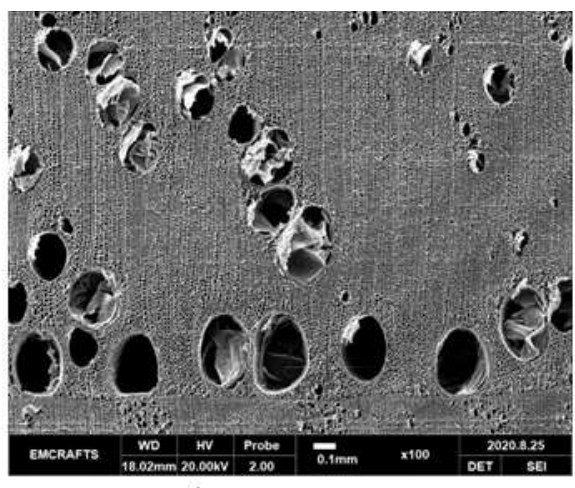

(b) Korean castanea

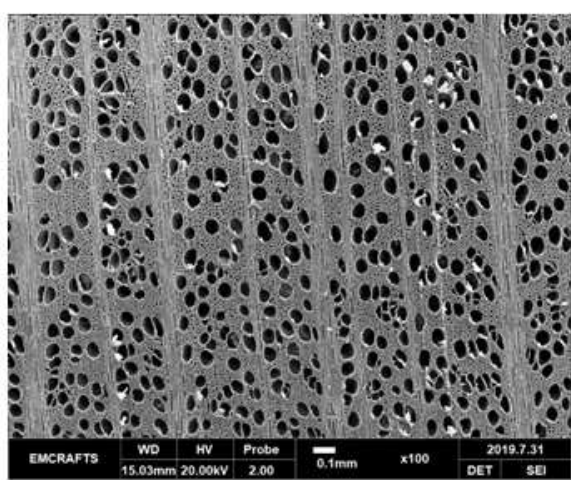

(e) Oriental plane tree

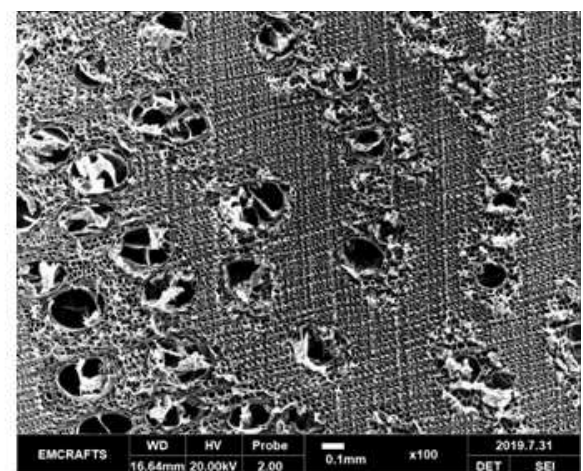

(c) East Asian hackverry

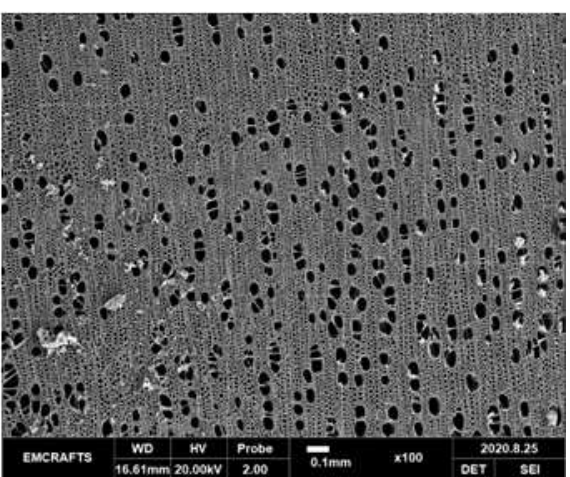

(f) East Asian alder

Fig 4. The morphologies of 6 species of cross-sectional hardwoods by SEM

\section{Figure 4}

The morphologies of 6 species of cross-sectional hardwoods by SEM

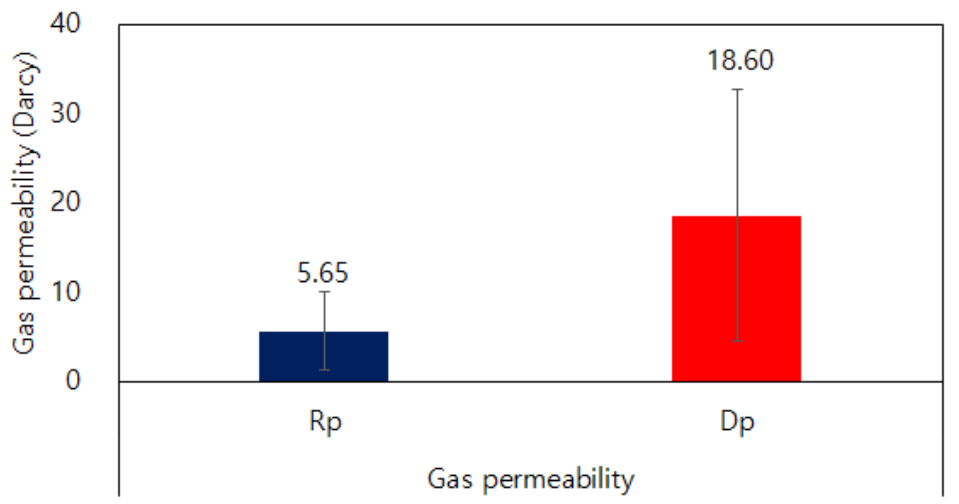

Fig. 5 Average difference of gas permeability between ring-porous wood (Rp) and diffuse-porous wood (Dp)

\section{Figure 5}


Average difference of gas permeability between ring-porous wood (Rp) and diffuse-porous wood (Dp)

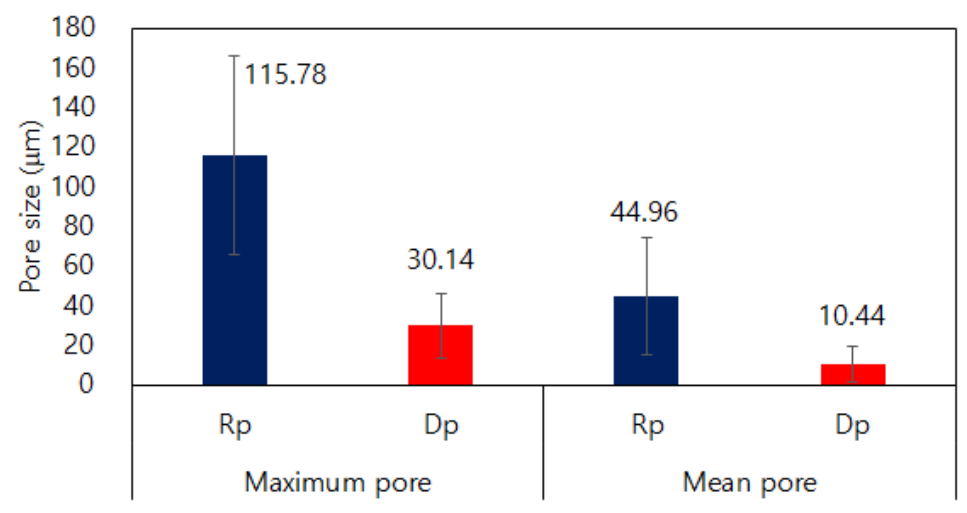

Fig. 6 Average difference of maximum pore size and mean pore size between ring-porous wood (Rp) and diffuse-porous wood (Dp)

\section{Figure 6}

Average difference of maximum pore size and mean pore size between ring-porous wood (Rp) and diffuse-porous wood (Dp)

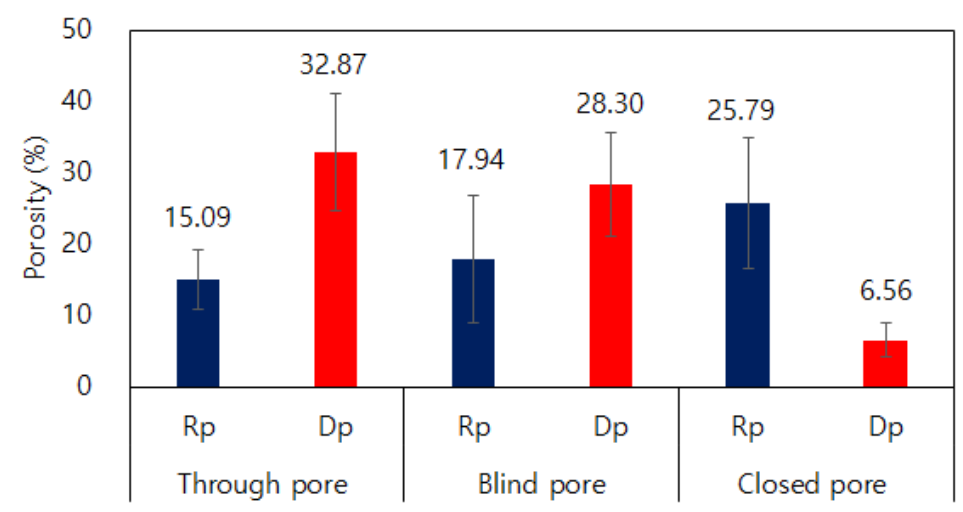

Fig. 7 Average difference of pore types between ring-porous wood (Rp) and diffuse-porous wood (Dp)

\section{Figure 7}

Average difference of pore types between ring-porous wood (Rp) and diffuse-porous wood (Dp) 


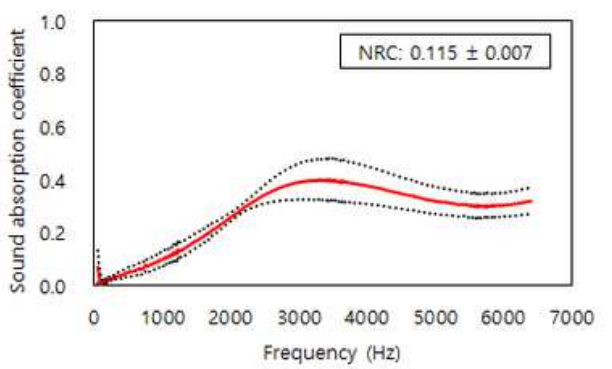

(a) Red toon

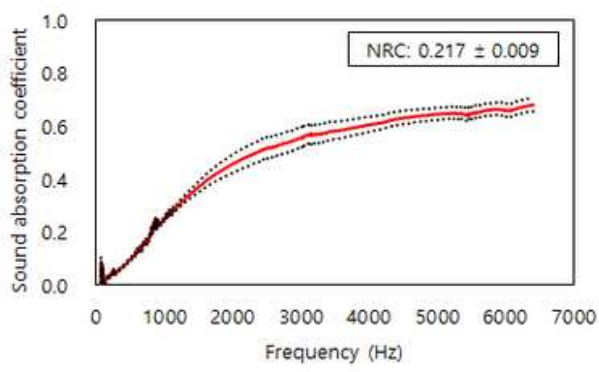

(d) Korean aspen

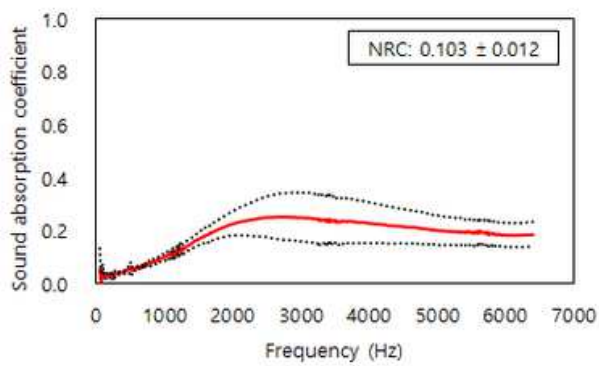

(b) Korean castanea

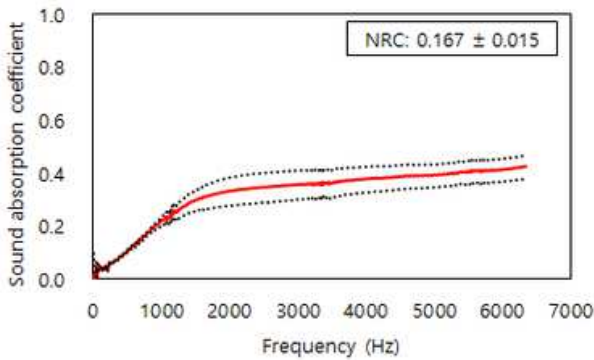

(e) Oriental plane tree

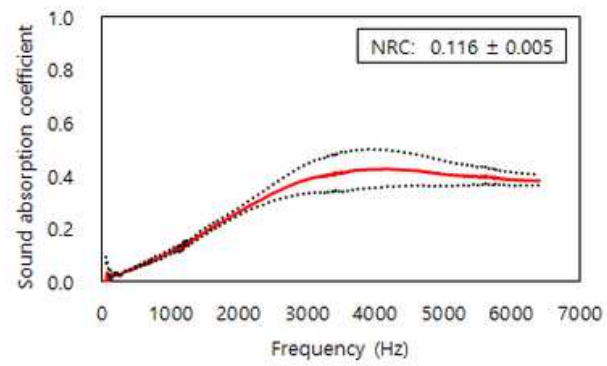

(c) East Asian hackverry

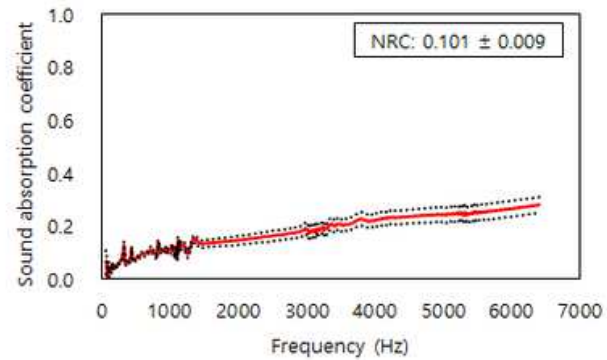

(f) East Asian alder

Fig 8. The sound absorption coefficient graph of 6 species of cross-sectional hardwoods

\section{Figure 8}

The sound absorption coefficient graph of 6 species of cross-sectional hardwoods

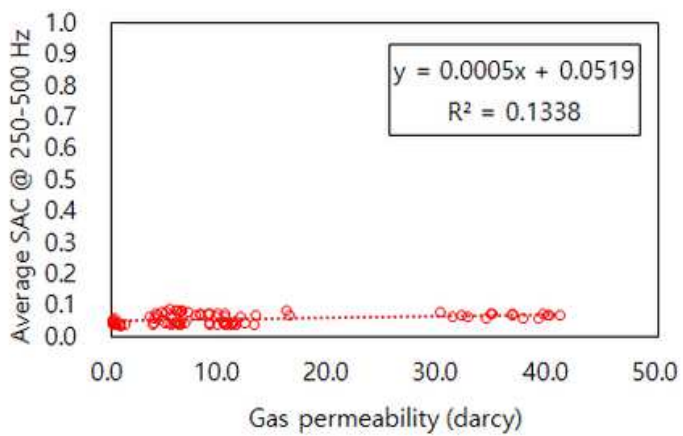

(a)

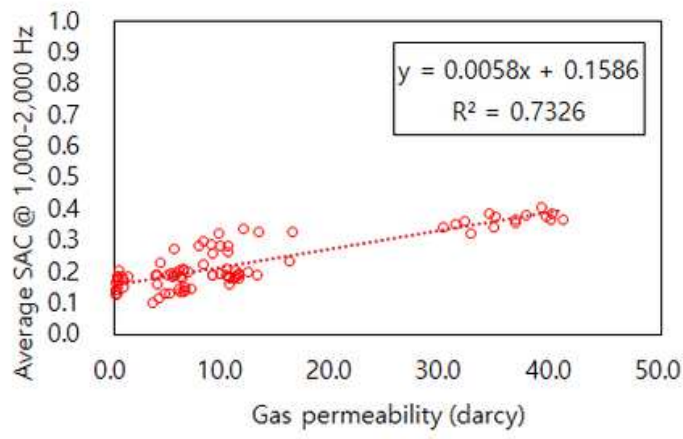

(c)

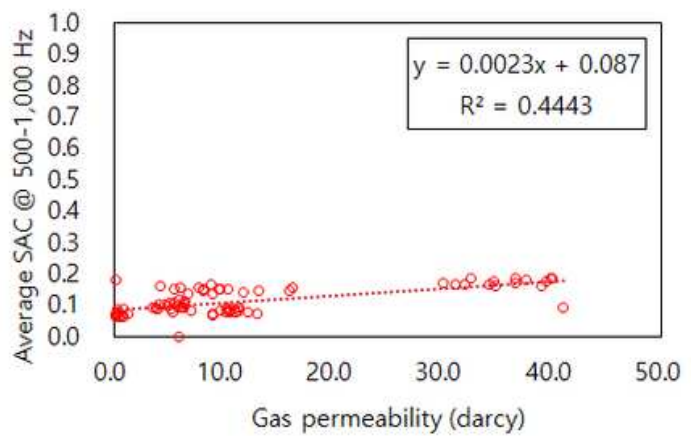

(b)

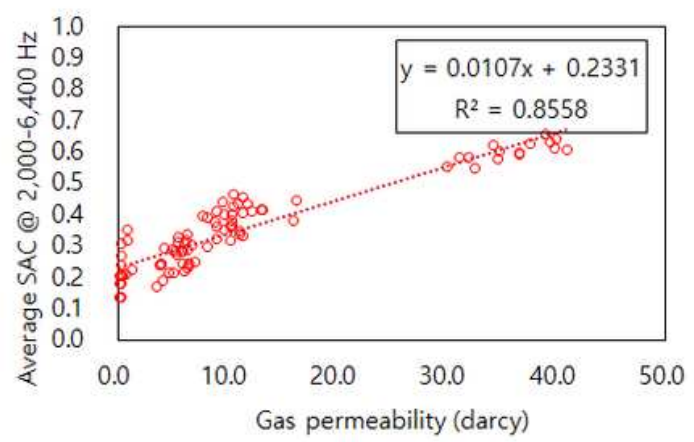

(d)

Fig. 9 Results of simple regression analysis between gas permeability and average $\mathrm{SAC}$ at $250-500 \mathrm{~Hz}$ (a), $\mathrm{SAC}$ at $500-1,000 \mathrm{~Hz}$ (b), $\mathrm{SAC}$ at $1,00-2,000 \mathrm{~Hz}$ (c), and $\mathrm{SAC}$ at $2,000-6,400 \mathrm{~Hz}$ (d), 
Results of simple regression analysis between gas permeability and average SAC at 250-500 Hz (a), SAC at $500-1,000 \mathrm{~Hz}$ (b), SAC at 1,00-2,000 Hz (c), and SAC at 2,000-6,400 Hz (d),

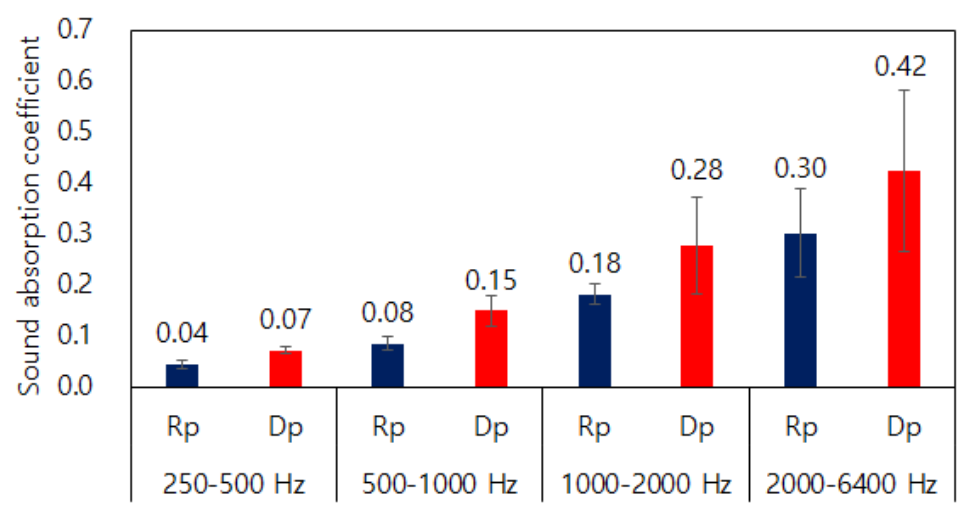

Fig. 10 Comparison of sound absorption coefficient between ring-porous wood (Rp) and diffuse-porous wood (Dp)

\section{Figure 10}

Comparison of sound absorption coefficient between ring-porous wood (Rp) and diffuse-porous wood (Dp)

\section{Supplementary Files}

This is a list of supplementary files associated with this preprint. Click to download.

- Table6species.pptx 